\title{
A prospective study on tumor like ovarian masses associated with pregnancy
}

\author{
G. Sravani1 ${ }^{1, *}$, M. Jyothsna ${ }^{2}$ \\ Assistant Professor, Dept. of Obstetrics and Gynecology, KIMS Academy, Puducherry, India
}

* Corresponding Author:

Email: anand_kims@yahoo.co.in

\begin{abstract}
Introduction: Pregnancy luteomas are non-neoplastic tumor like masses found in the ovary. These pregnancy luteomas spontaneously regress after delivery. Luteomas are usually asymptomatic and found incidentally during cesarean section or radiological imaging.

Materials and Methods: A two year prospective study was done on 450 pregnant women while undergoing cesarean section. While doing cesarean section surgeons found ovarian masses of varying size in a few patients, these masses we suspected to be an ovarian neoplasm. salpingo-oophorectomy was performed in these pregnant women. Post operatively the excised ovaries with fallopian tube were sent for histopathological examination.

Results: Out of 450 cesarean section, ovarian mass were found incidentally in $16(3.5 \%)$ cases out of which 3 (0.6\%) were luteomas.

Conclusion: Recognition of these luteomas is important during cesarean section, so that unnecessary oophorectomy is avoided which is risky and can prevent unnecessary complication for both the mother and the fetus.
\end{abstract}

Keywords: pregnancy luteomas, Cesarean section, ovaries, Histopathological examination.

\section{Introduction}

Luteoma of pregnancy is a benign, hyperplastic tumor like lesion of the ovary. In 1966 Pregnancy luteomas were first described by Sternberg and Barclay. ${ }^{1}$ Many of the cases resolve completely after delivery during post partum period. ${ }^{2}$ Luteomas are rare, they are asymptomatic and are found incidentally at the time of cesarean section or postpartum tubal ligation. ${ }^{3}$ During cesarean section an accurate diagnosis is important, since it can mimic with malignancy of ovaries leading to unnecessary oophorectomy, with has concomitant risk to both fetus and mother. ${ }^{4}$ In approximately $25 \%$ of women with pregnancy luteoma hyper secretion of androgens occurs; and from $10 \%$ to $50 \%$ of these women will have the clinical signs of hyperandrogenism. ${ }^{5}$

\section{Materials and Methods}

This is the two years prospective study conducted in a teaching hospital. During these two years all the pregnant women who were admitted in teaching hospital for cesarean section were included in the study. Pregnant women below 25 years of age and above 40 years were excluded from the study. Age from 25 years to 40 years pregnant women who has undergone cesarean section were included in the study. During cesarean section the incidentally found ovarian masses which we were suspecting to be malignant ovaries were excised by performing salpingo-oophorectomy. After salpingo-oophorectomy the ovaries with fallopian tubes were submitted for histopathological examination. The specimens were fixed overnight in $10 \%$ formalin and tissue processing were started and submitted to pathologist for histopathological diagnosis.

\section{Results}

In the present two year prospective study out of 450 cesarean sections which were performed on pregnant women, ovarian mass were found incidentally in $16(3.5 \%)$ cases out of which three $(0.6 \%)$ were luteomas, 9 cases showed features of mucinous cystadenomas, two ovarian specimens were serous cystadenomas, one ovarian mass showed features of mucinous cyst adenocarcinoma and one was granulosa cell tumor. The histopathological diagnosis of 16 ovarian masses were shown in Table-I. Macroscopic examination showed all the 16 ovarian masses were enlarged measuring from $4 \mathrm{~cm}$ to $10 \mathrm{~cm}$ in diameter. In few ovarian masses the cut surface showed multiple nodules which were well circumscribed and soft in consistency with yellow to grey brown in colour. Microscopic features of these sections studied showed round, oval to polygonal cells which were arranged in monolayer sheets with abundant eosinophilic granular cytoplasm and the nuclear features were round to oval vesicular nucleus. All these microscopic features suggests the diagnosis of pregnancy luteoma. Steroid cell tumor and Leydig cell tumor were ruled out because Reinke crystals were not found in the studied microscopic sections and even there were no areas of necrosis and mitosis.

\section{Discussion}

Luteomas of pregnancy are rare non neoplastic conditions, which these are confused with the solid malignant or benign ovarian neoplasms. ${ }^{6}$ It most often occurs in the multiparous state and in third and fourth decade of life. The increased prevalence is seen in the African American population. In $50 \%$ of cases it is multinodular and one third of cases showed bilateral 
ovarian luteomas. ${ }^{7}$ Garcia-Bunuel et al. in their study in 1975 have reported the pregnancy luteoma in 20 patients that is the maximum number of cases reported till date. ${ }^{2}$ In present study we reported three cases out of 450 cesarean sections and all the three cases were seen in the age group of above 30 years.

Pregnancy luteomas regress spontaneously during postpartum period. ${ }^{8}$ pregnancy luteomas are variable in size ranging from lessthan $1 \mathrm{~cm}$ to over $20 \mathrm{~cm}$ in diameter. Large luteomas rarely can cause torsion, resulting in acute abdominal pain. ${ }^{7}$ Polycystic ovary syndrome is a predisposing condition for pregnancy luteomas. ${ }^{4}$ Clinically, Serum testosterone levels reach to normal level within two weeks during postpartum period and luteomas are often asymptomatic and only found incidentally during cesarean section. ${ }^{1}$ similarly in the present study all the luteoma cases were silent and found incidentally during cesarean section and the largest luteoma was $10 \mathrm{~cm}$ in diameter.

Macroscopic examination of luteomas shows that luteomas are solid to soft in consistency and cut surface shows tan or flesh colored, with hemorrhagic foci. ${ }^{2}$ Microscopically pregnancy luteomas shows circumscribed nodules. These nodules are composed of round to oval to polygonal cells arranged in monolayer sheets, cords or small clusters. The cytoplasm of these cells shows abundant eosinophilic and granular cytoplasm. The nuclei may be slightly pleomorphic and hyperchromatic nuclei. ${ }^{9}$ These cells are surround by follicle like spaces containing colloid like material. Similarly in this present prospective study all the three cases was found incidentally during cesarean section and showed similar pathological findings both macroscopically and microscopically.

In few studies It showed that in one fourth of the cases, Pregnancy luteomas are hormonally active which is leading to secretion of androgens and causing virilization and maternal hirsutism. ${ }^{10}$ Malignant ovarian neoplasms are rare in pregnant women. But in the present two year prospective study only one ovarian mass showed features of mucinous cystadenocarcinoma. The granulosa cell tumors, Sertoli-Leydig cell tumors, pure Leydig (hilar) cell tumors, thecomas, stromal luteomas, unclassified sex cord-stromal tumors, stromal hyperthecosis and hyperreactio luteinalis are the differential diagnosis for pregnancy luteomas. ${ }^{11}$ However; in the present study, Reinke crystals were not found in the sections studied; therefore Leydig cell tumor and steroid cell tumor were ruled out.

\section{Conclusion}

To conclude, pregnancy luteomas regress spontaneously after delivery. So, proper clinical and radiological diagnosis is important during pregnancy period or during cesarean section to avoid unnecessary excision of ovaries.
Table 1: Showing Histopathological Diagnosis of Ovarian Masses

\begin{tabular}{|c|l|c|}
\hline $\begin{array}{c}\text { S. } \\
\text { No }\end{array}$ & \multicolumn{1}{|c|}{$\begin{array}{c}\text { Histopathological } \\
\text { Diagnosis }\end{array}$} & $\begin{array}{c}\text { Number of } \\
\text { Cases }\end{array}$ \\
\hline 1 & Luteoma of pregnancy & 3 \\
\hline 2 & Mucinous Cystadenoma & 9 \\
\hline 3 & Serous Cystadenoma & 2 \\
\hline 4 & $\begin{array}{l}\text { Mucinous } \\
\text { Cystadenocarcinoma }\end{array}$ & 1 \\
\hline 5 & Granulosa cell Tumor & 1 \\
\hline
\end{tabular}

\section{References}

1. Sternber g WH, Barclay DL. Luteoma of pregnancy. Am J Obstet Gynecol 1966;95:165-84.

2. Garcia-Bunuel R, Berek JS, Woodruff JD. Luteomas of pregnancy. Obstet Gynecol 1975;45:407-14..

3. Janovski NA, Paramanandhan TL. Ovarian tumors. Tumors and tumor-like conditions of the ovaries, fallopian tubes and ligaments of the uterus. Major Probl Obstet Gynecol 1973;4:1-245.

4. Phelan N, Conway GS. Management of ovarian disease in pregnancy. Best Pract Res Clin Endocrinol Metab 2011;25:985-92.

5. Verhoeven AT, Mastboom JL, van Leusden HA, van der Velden WH. Virilization in pregnancy coexisting with an (ovarian) mucinous cystadenoma: A case report and review of virilizing ovarian tumors in pregnancy. Obstet Gynecol Surv 1973;28:597-622.

6. Sternberg WH. Nonfunctioning ovarian neoplasms. In: Grady HG, editor. The Ovary. Baltimore: William \& Wilkins; 1963. p. 209.

7. Clement PB. Tumor-like lesions of the ovary associated with pregnancy. Int J Gynecol Pathol 1993;12:108-15.

8. Wang HK, Sheu MH, Guo WY, Hong CH, Chang CY Magnetic resonance imaging of pregnancy luteoma. $\mathrm{J}$ Comput Assist Tomogr 2003;27:155-7.

9. Robert HY, Philip BC. Miscellaneous primary tumors, secondary tumors, and nonneoplastic lesions of ovary. Diagnostic Surgical Pathology, Sternberg's. 5th ed. Lippinco $\square$ Williams and Wilkins, Philadelphia; 2010. p. 2365-6.

10. Zander J, Mickan H, Holzmann K, Lohe KJ. Androluteoma syndrome of pregnancy. Am J Obstet Gynecol 1978;130:170-7.

11. Tinkanen H, Kuoppala T. Virilization during pregnancy caused by ovarian mucinous cystadenocarcinoma. Acta Obstet Gynecol Scand 2001;80:476-7. 